\title{
ARTIGO N²
}

A BIODIVERSIDADE E O TURISMO REGIONAL

\section{FATORES DE RESILIÊNCIA URBANA NAS CIDADES DE}

CABREUVA, ITU E SALTO.

BIODIVERSITY AND REGIONAL TOURISM

FACTORS OF URBAN RESILIENCE IN THE CITIES

CABREUVA, ITU AND SALTO

Deize Sbaral SANChes Ximenes 


\title{
A BIODIVERSIDADE E O TURISMO REGIONAL FATORES DE RESILIÊNCIA URBANA NAS CIDADES DE CABREUVA, ITU E SALTO.
}

\author{
Deize Sbarai Sanches Ximenes* \\ *Mestre em Arquitetura e Urbanismo - PósArq da UFSC - Brasil. \\ E-mail: sanchesarquiteta@uol.com.br
}

\begin{abstract}
RESUMO
Os assentamentos urbanos alteram e agridem o ecossistema natural fazendo com que seja necessário criar diretrizes de planejamento socioambiental e econômico para a elaboração de projetos sustentáveis. A biodiversidade e o turismo regional são abordados como fatores essenciais para o fortalecimento da resiliência urbana nas cidades de Itu, Salto e Cabreúva; região com grande potencial turístico por pertencer ao Roteiro dos Bandeirantes, e um rico patrimônio natural e paisagístico, oferecendo condições de desenvolver propostas de planejamento urbano sustentável para colaborar com possíveis intervenções dos órgãos públicos estaduais e municipais na formulação e revisão de planos diretores e contribuir com a valorização das potencialidades dos municípios regionais.
\end{abstract}

Palavras-chave: biodiversidade, resiliência urbana, turismo regional, projeto sustentável.

\author{
BIODIVERSITY AND REGIONAL TOURISM \\ FACTORS OF URBAN RESILIENCE IN THE CITIES \\ CABREUVA, ITU AND SALTO
}

\begin{abstract}
Urban settlements change and harm the natural ecosystem, making necessary to create guidelines of social environmental and economic planning for the development of sustainable projects. Biodiversity and regional tourism are considered as essential factors for strengthening urban resilience in the cities Itu, Salto and Cabreúva , which are located in a region with great tourist potential because they belong to the Roteiro
\end{abstract}


dos Bandeirantes ${ }^{1}$ (Bandeirantes' Route), with a rich landscape and natural heritage, offering conditions to develop proposals of sustainable urban planning to collaborate with possible assistance to State and Local government agencies in the formulation and revision of master plans as well as to contribute with the enhancing of potentialities of the regional cities.

Keywords: biodiversity, resilience urban, regional tourism, sustainable design.

\section{INTRODUÇÃO}

O número de habitantes do planeta cresceu, atingindo hoje os sete bilhões (worldometers, 2013). Se a população urbana continuar crescendo conforme as tendências atuais, até 2050 , a população mundial urbana alcançará 9,731 bilhões de habitantes, segundo o Instituto francês de Estudos Demográficos (INED), e deverá ocorrer, principalmente, nos países em desenvolvimento, que concentrarão $85 \%$ da população mundial.

Atualmente, a concentração global da população nas cidades, vem promovendo o aumento do consumo da energia e dos recursos naturais, acarretando a falta de conservação das áreas verdes, uso inadequado do solo e da água, poluição do ar, transporte ineficiente e graves implicações para a biodiversidade urbana; como, a fragmentação dos habitats que interfere na conservação dos ecossistemas, aumento de espécies invasoras não nativas, aumento da área de perturbação dos animais nativos e uma transformação dos organismos que ali vivem. É necessário pensar na recuperação do ambiente urbano e melhorar a qualidade de vida da população atual, assim como das gerações futuras sem agredir o ambiente natural e os ecossistemas.

Em um contexto de mudanças climáticas globais, as cidades tendem a ser atingidas por fenômenos climáticos de maior frequência e intensidade. Torna-se necessário uma maior compreensão da interação entre a urbanização, políticas urbanas e a qualidade do meio ambiente. É de extrema importância a criação de diretrizes de planejamento socioambiental e econômico para a elaboração de projetos urbanos mais sustentáveis, colaborando para a resiliência das cidades. A adaptação das cidades às mudanças climáticas, para que se tornem resilientes aos impactos que já estão

\footnotetext{
${ }^{1}$ Bandeirantes were the members of colonial exploratory expeditions.
} 
ocorrendo em todo o planeta, como: inundações, deslizamentos, desertificação, falta d'água, corte de suprimentos de energia e matéria, entre outros, é um desafio que precisamos enfrentar.

Este trabalho tem como base, os princípios da resiliência urbana, a qual pode ser definida como a capacidade do ecossistema de manter ou retornar às suas condições originais após um distúrbio provocado por forças naturais ou pela ação humana, o turismo regional como fator de integração socioambiental e a biodiversidade urbana indispensável para a sobrevivência das comunidades.

\section{RESILIÊNCIA URBANA}

Construir cidades mais resilientes pode estar agregado ao desenvolvimento do potencial turístico regional, estimulando trajetórias de desenvolvimento mais sustentáveis e mais preparadas para lidar com as grandes tendências evolutivas e seus impactos. Neste sentido são necessárias abordagens conceituais e instrumentais de avaliação da sustentabilidade urbana que permitam pensar os territórios e os processos de desenvolvimento sob o foco da resiliência, enquanto capacidade estratégica para se adaptarem a contextos de crise e perturbação.

Para a elaboração de um projeto sustentável em territórios, como regiões, cidades ou comunidades locais, é necessária a capacidade de adaptação face às grandes tendências evolutivas de carência econômica, social e ambiental segundo a perspectiva da resiliência; a qual refere à capacidade de um sistema absorver perturbações e reorganizar-se, enquanto está sujeito a forças de mudança, sendo capaz de manter o essencial das suas funções, estrutura, identidade e mecanismos (Walker et al., 2004). De acordo com o relatório Urban Resilience Research Prospectus (CSIRO, 2007), a resiliência urbana não é resposta a um impacto, mas sim a capacidade de mudança e adaptação contínua, considerando os seus fluxos, as suas dinâmicas sociais, as redes de governança e o ambiente biofísico.

O turismo pode ser visto como um fator de sustentabilidade social, ambiental e econômico que reforça o conceito de cidades resilientes. Entenda-se o turismo como uma atividade de fundamental importância para a sociedade e um dos principais fatores de interação socioambiental e de integração política, cultural e econômica num mundo cada vez mais globalizado. $O$ turismo pode contribuir para a resiliência urbana com 
investimentos, oferecidos pelos órgãos públicos e privados, na conservação e manutenção dos recursos naturais, na infraestrutura básica, como os sistemas de saneamento, de transporte, de comunicações e de saúde; na geração de mais emprego e renda para a população local, no uso de tecnologias ambientalmente saudáveis que não degradem o ambiente, na utilização de fontes limpas de energia e na valorização dos patrimônios ambientais, culturais e históricos regionais.

As cidades dependem da biodiversidade e dos ecossistemas, tanto no ambiente urbano, como além dele, com sua vasta variedade de bens e serviços, que são essenciais para o desenvolvimento econômico e para a sustentabilidade socioambiental. $\mathrm{O}$ ecossistema mantém o potencial das cidades, regulando o clima, protegendo as cidades contra riscos, atendendo as necessidades de energia e agricultura, prevenindo a erosão do solo, oferecendo oportunidades pra recreação e inspiração cultural.

\section{BIODIVERSIDADE}

Entenda-se por Biodiversidade, a variabilidade de organismos vivos de qualquer fonte, incluindo os ecossistemas terrestres e marinhos e outros ecossistemas aquáticos e os complexos ecológicos dos quais formam parte; compreende a diversidade dentro de cada espécie, entre espécies e entre os ecossistemas (Convenção sobre Diversidade Biológica, 1992). A diversidade de habitats encontrados nos aglomerados humanos vai desde a franja rural até o núcleo urbano, tendo como paisagens dos habitats; as remanescentes de paisagens naturais - restos de florestas primitivas, as paisagens agrícolas tradicionais - prados e áreas de terra arável e as paisagens urbano-industrial - centros urbanos, áreas residenciais, parques industriais, áreas ferroviárias, parques e jardins formais.

\section{PROBLEMATIZAÇÃO}

Mascaró (2005) alerta que os assentamentos urbanos alteram e agridem em maior ou menor grau o ecossistema natural do terreno e que o novo sistema ecológico criado poderá ser agradável ou não, estável ou instável, econômico ou antieconômico, dependendo, em grande parte, do critério com que o urbanista o trata.

De acordo com o PNUMA (Programa das Nações Unidas para o Meio Ambiente), as 
mudanças climáticas e as altas taxas de emissão de gases de efeito estufa acarretarão, até 2030 , um aumento de 4C na temperatura global e provocarão diversos efeitos catastróficos, como a fragilidade da população, o esgotamento e a destruição das florestas e da biodiversidade, das quais depende a sobrevivência de muitas comunidades e a falta de manutenção e conservação da paisagem natural e da fauna. Estes são os principais aspectos que nos levam a estudar formas de tornar as cidades mais resilientes partindo do seu potencial turístico, ambiental e paisagístico no território municipal das cidades de Cabreúva, Itu e Salto, conectadas pela Roteiro dos Bandeirantes.

\section{ESTUDO DE CASO}

A área de estudo compreende os municípios de Itu, Salto e Cabreúva, os quais se desenvolveram à margem do Rio Tietê (Figura 1); um importante elemento no desenvolvimento do Estado e na formação de diversos povoados. Apesar de seu elevado grau de poluição, tem um importante valor estético e um rico cenário turístico devido á presença da diversidade de patrimônio natural, histórico e cultural, sendo ele o principal elemento paisagístico de ligação dos municípios.

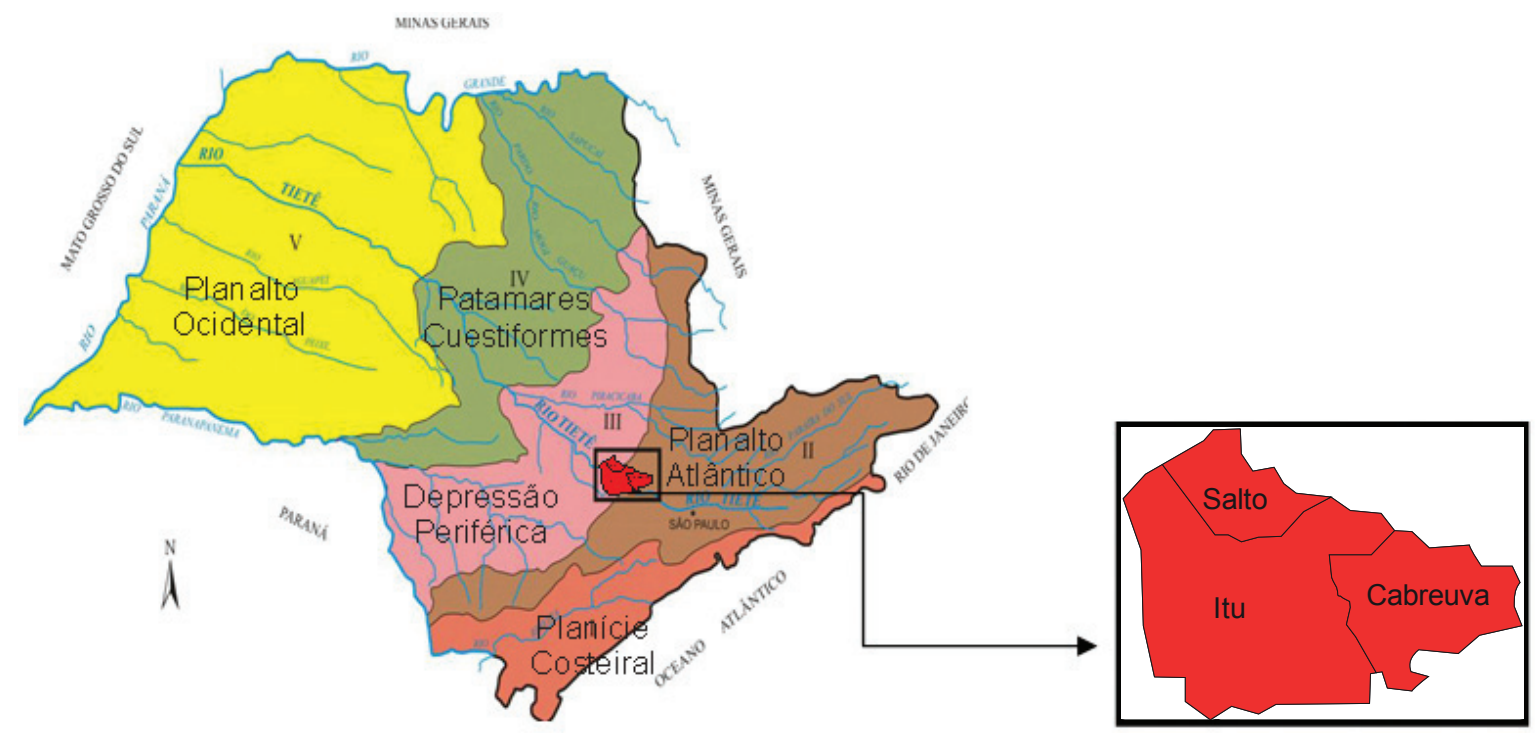

Figura 1: Localização da Área de Estudo e o Rio Tietê. Fonte: Carpi, 2009

No Vale do Médio Tietê do Estado de São Paulo, onde está localizada a nossa área de estudo, concentram-se importantes elementos de patrimônio natural, entre eles: a Zona de Transição, o Planalto Atlântico e a Depressão Periférica (Figura 2). A área de transição entre o Planalto Atlântico e a Depressão Periférica é caracterizada pela exis- 
tência de uma "fall line", ou linha de quedas, que compreende algumas cachoeiras, corredeiras e pequenas quedas, como a cachoeira do rio Tietê (Salto de Itu-Guaçu), em Salto. A presença dessa linha de quedas foi a responsável pelo início da industrialização em Sorocaba, Itu e Salto no início do séc. XX, pois permitiu o aproveitamento da energia elétrica para o funcionamento das primeiras fábricas, algumas em funcionamento até os dias atuais (CARPI, 2009).O Planalto Atlântico consiste na área mais elevada do Estado de São Paulo, geralmente acima de 700 m, com planaltos, serras, morros, vales encaixados e declividade mais acentuada, ocupada originariamente por matas, e a Depressão Periférica Paulista, que corresponde a uma área relativamente rebaixada em relação aos arredores, com altitudes geralmente entre 500 m e 700 m, onde predomina o relevo de colinas amplas e suaves, com pequena declividade, ocupado inicialmente por matas ciliares, cerrados e campos.



Figura 2: Compartimentos naturais e localização dos municípios. Fonte: IGC, 1998.

Os municípios de Cabreúva, Salto e Itu, mesmo com suas dimensões territoriais e densidades demográficas bem distintas, fazem parte de um importante circuito turístico regional de Itupararanga Sorocabana - Roteiro dos Bandeirantes (Figura 3). 


\section{ESTADO DE SÃO PAULO}

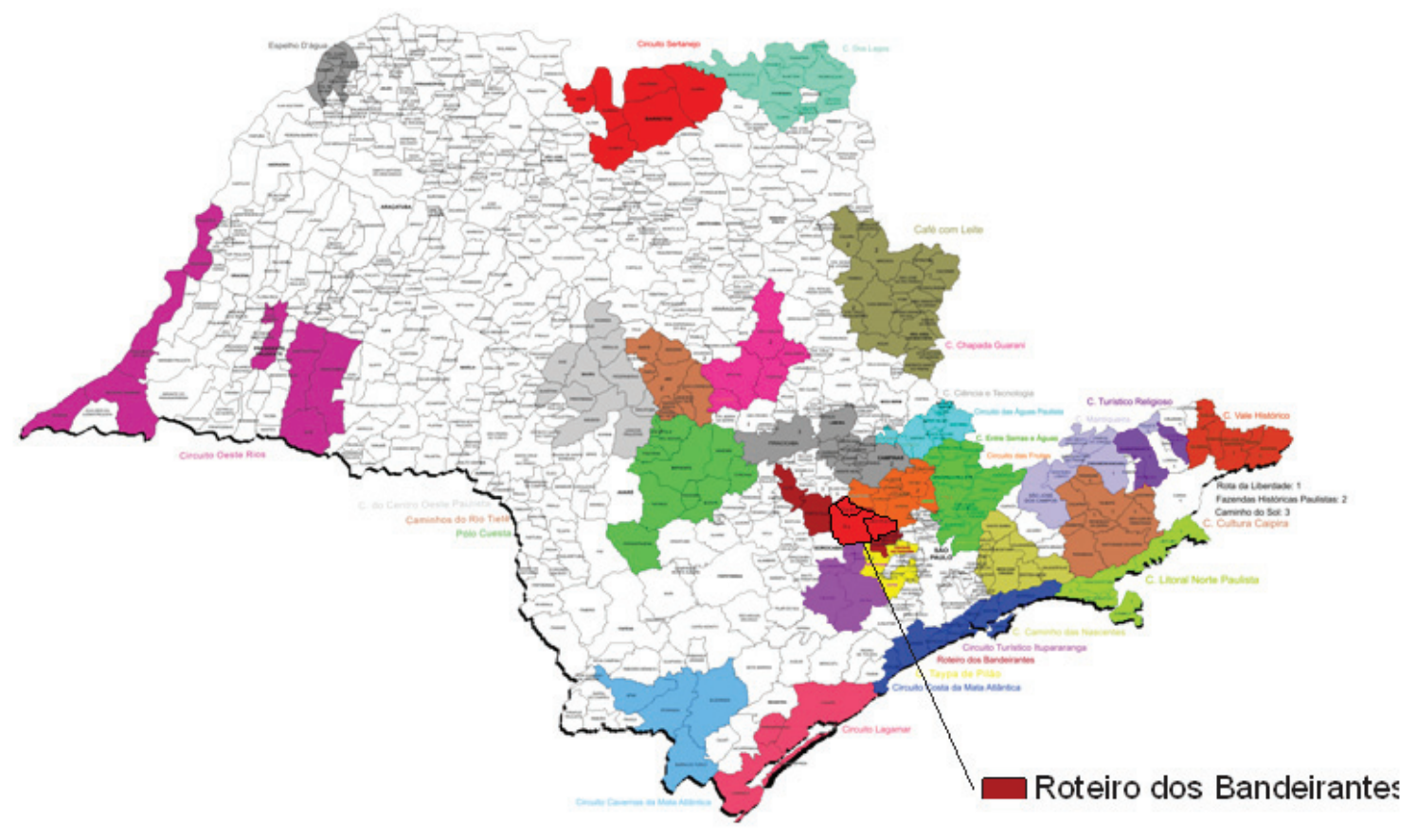

Figura 3: Roteiro dos Bandeirantes. Fonte: http://www.turismo.sp.gov.br/

Ele engloba oito cidades paulistas num percurso de 180 quilômetros que inicia em Santana do Parnaíba, passa por Pirapora do Bom Jesus, Araçariguama, Cabreúva, Itu, Salto e Porto Feliz até chegar à cidade de Tietê.As cidades do Roteiro fazem parte de um polo de referência histórico-cultural para o Brasil, inserido em um projeto maior, denominado Circuito Turístico da Hidrovia Tietê-Paraná, que congrega 86 municípios em 900 quilômetros navegáveis.

Este trabalho em andamento parte do pressuposto que a biodiversidade e o turismo regional podem colaborar para a resiliência das cidades de Cabreúva, Itu e Salto a partir do eixo de ligação entre os municípios; o Roteiro dos Bandeirantes.

Cabreúva, o município de menor porte, com 45.112 habitantes (IBGE 2012) e área equivalente à $260,234 \mathrm{~km}^{2}$, proporciona uma densidade demográfica de $159,87 \mathrm{hab} / \mathrm{km}^{2}$, possui aproximadamente $40 \%$ da Serra do Japi (Figura 4), compartilhando com Pirapora do Bom Jesus outros $10 \%$ dessa importante vegetação remanescente de planalto do Estado de São Paulo (RAIMUNDO, 2006). Localizada a 78 quilômetros da capital paulista, a cidade é uma opção de turismo ecológico e de aventura, pois está dentro de uma área de preservação ambiental com muitas cachoeiras, grutas (Figura 5) e trilhas. 


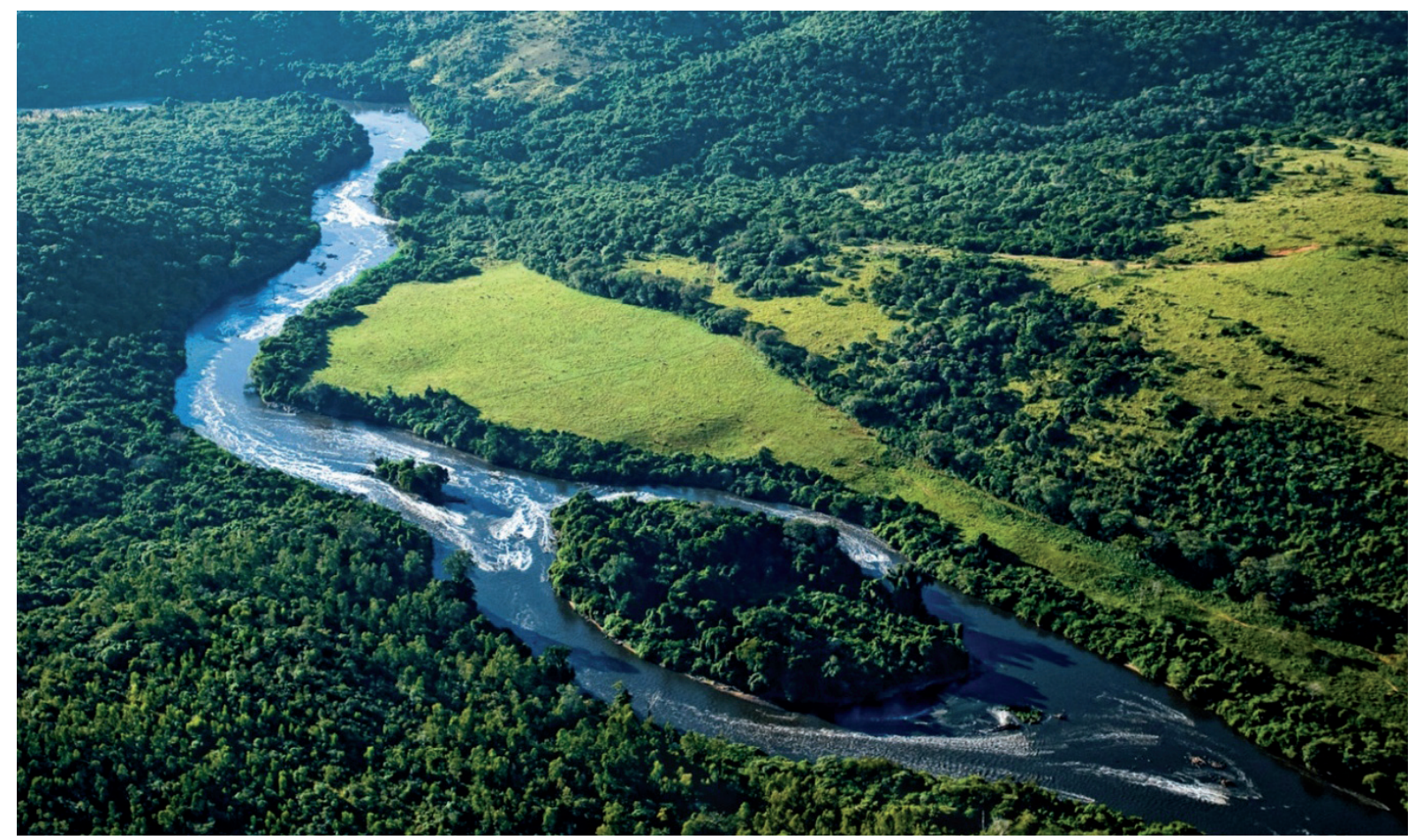

Figura 4: Serra do Japi, um Oásis da Mata Atlântica cortada pelo Rio Tietê.

Fonte: www.edhorizonte.com.br

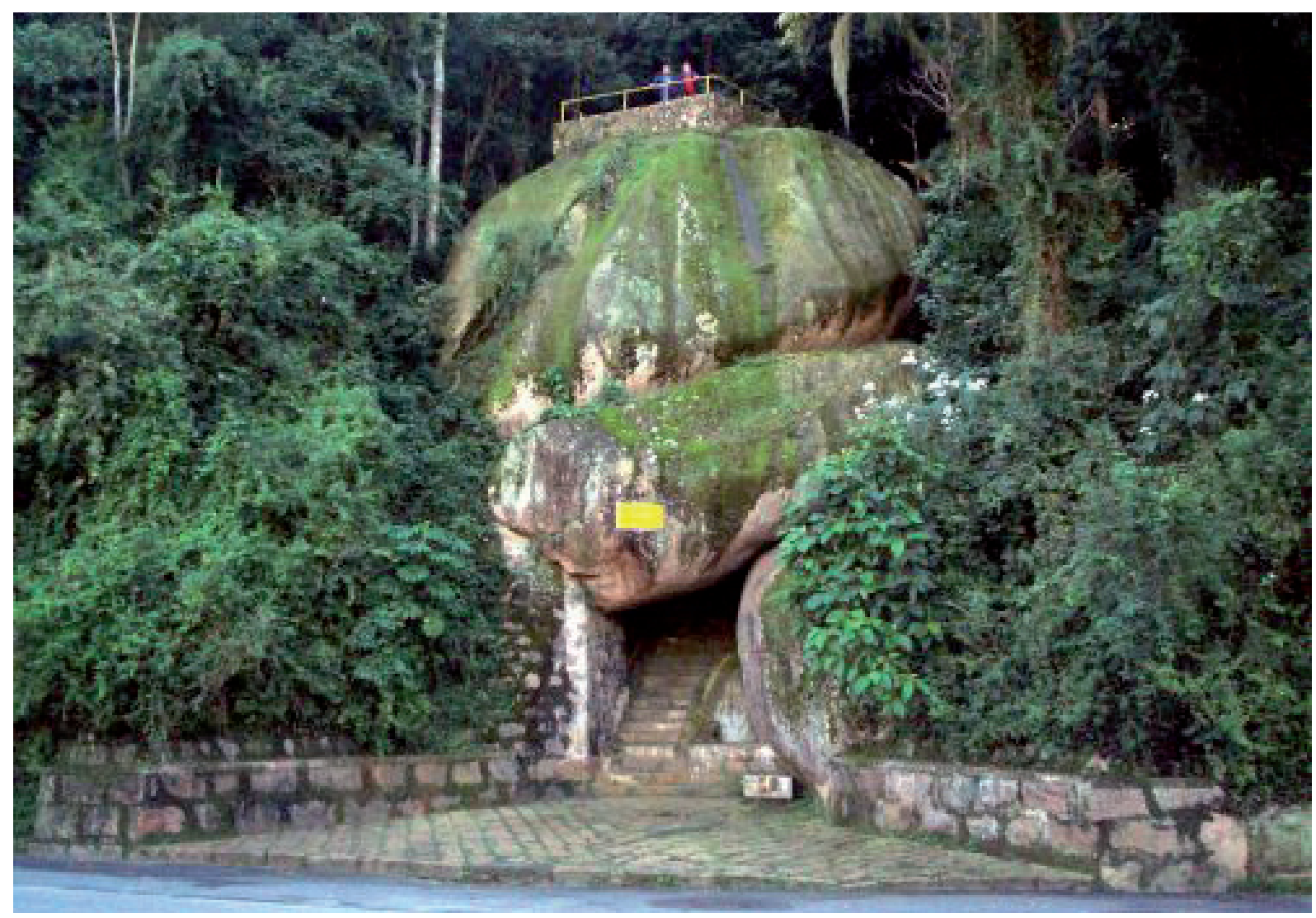

Figura 5: Gruta da Glória - Itu. Fonte:www.webventureuol.uol.com.br 
O município de Salto, de médio porte, tem sua população estimada em 112.052 habitantes (IBGE 2012), ocupando uma áreade 133,205 km² e densidade demográfica de $792,13 \mathrm{hab} / \mathrm{km}^{2}$ (IDH 0,809). O antigo povoado de Salto surgiu de um aldeamento de índios guaianazes localizado na margem do Rio Tietê em 1695. Hoje, a cidade é cortada pelo rioe classificada como estância turística do interior do estado de São Paulo.

O município de Itu, a cidade de maior porte da pesquisa, com 163.882 habitantes (IBGE 2012) e $639,9578 \mathrm{~km}^{2}$, densidade demográfica $241,01 \mathrm{hab} / \mathrm{km}^{2}$, possui uma arquitetura da época imperial e se caracteriza pelo seu patrimônio histórico, artístico, arqueológico e natural; como a Fábrica de Tecidos São Luiz (Figura 6), fundada em 1869 e primeira indústria a vapor do Estado de São Paulo, as fazendas tombadas da época do café (Figura 7) e o centro histórico (Figura 8) em meio a um relevo de colinas suaves.
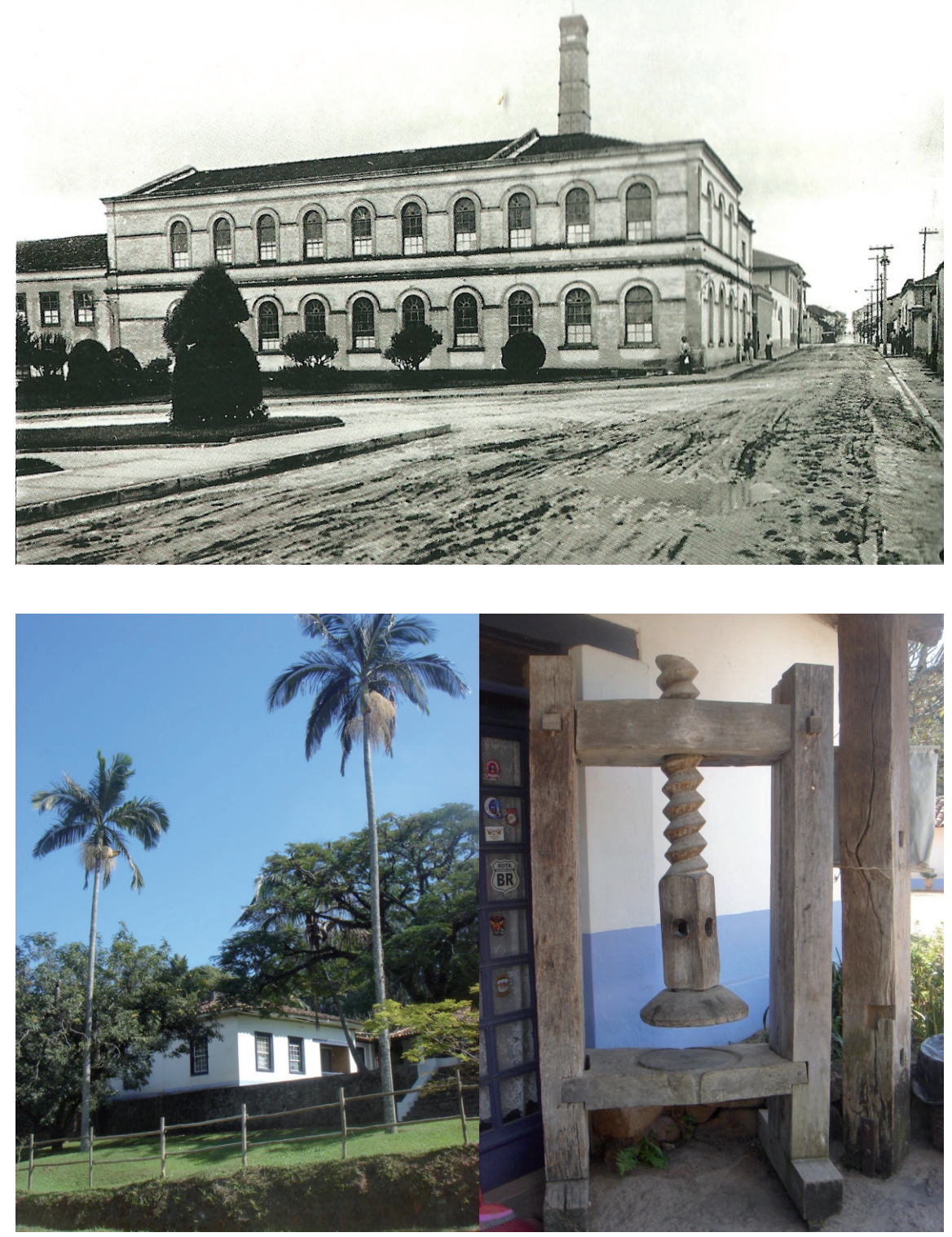

Figura 6: Antiga Fábrica de Tecidos São Luiz - 1869. Fonte: Ituantiga.blogspot.com

Figura 7:

Fazenda do Chocolate.

Fonte: Deize Sanches, 2013 


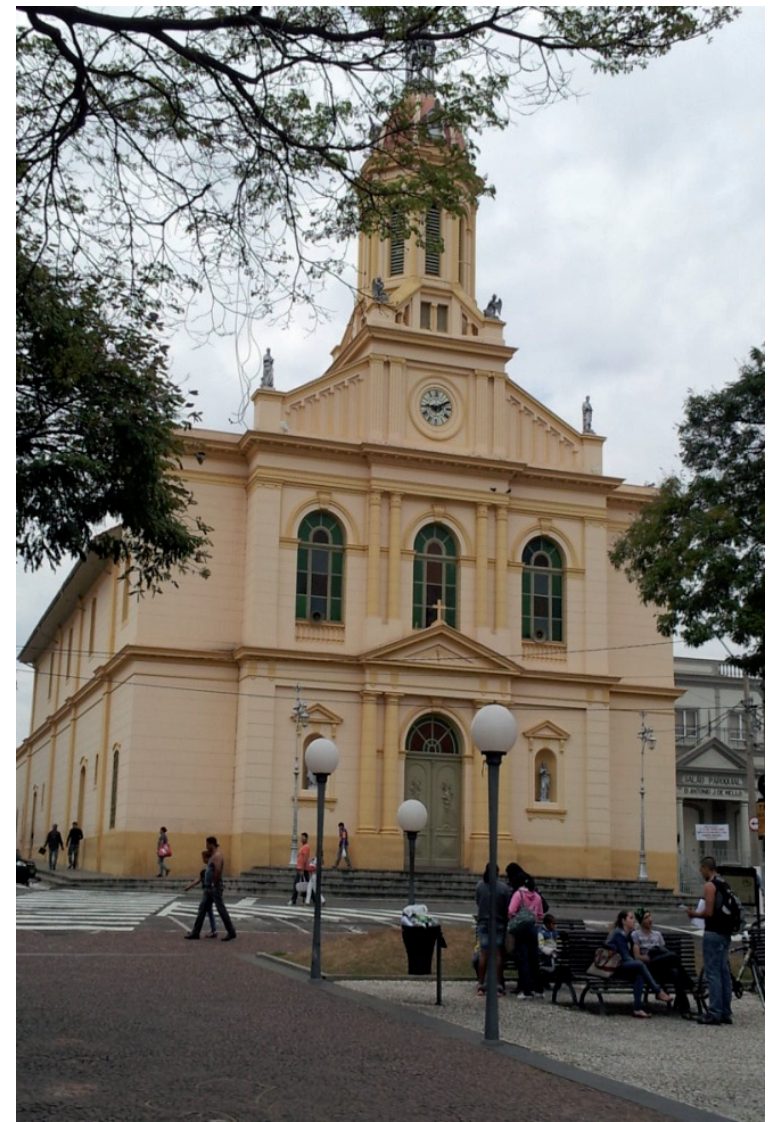

Figura 8: Centro Histórico de Itu. Fonte: Deize Sanches, 2013
Atualmente, as políticas de desenvolvimento do turismo estão associadas à proteção ambiental, a eficiência econômica e a justiça social. Neste sentido, a responsabilidade socioambiental surge como um grande diferencial para o setor turístico, que, ao promoverem o turismo sustentável, contribuem para o desenvolvimento econômico e socioambiental das comunidades dos municípios em estudo.

Os municípios possuem uma pequena distância entre os pólos econômicos regionais; à $100 \mathrm{Km}$ de São Paulo e Campinas e $30 \mathrm{Km}$ de Sorocaba, e são interligadas pelos principais eixos rodoviários do oeste paulista por onde se realiza a dispersão urbano-industrial da Grande São Paulo em direção ao inteiros. A Rodovia Anhanguera e a Rodovia Castelo Branco foram construídas respectivamente nas décadas de 1940 e 1960, devido ao movimento expansionista rumo ao interior do Estado de São Paulo. A rodovia Anhanguera foi projetada com um traçado simples; enquanto a Castelo Branco foi construída sobre uma nova escala: aumento do número de faixas para três, canteiro central mais largo que impede o ofuscamento da visão e mudanças de rampas e raios de curvatura que facilitam o tráfego (REIS, 2010).

O desenvolvimento do potencial econômico da região pode ser analisado a partir da década de 1920 , onde cerca de $30 \%$ da produção industrial paulista era proveniente do interior, sobretudo das regiões de Sorocaba e de Campinas pela Antiga Estrada de Itu, onde concentravam 21,2\% dos operários do Estado de São Paulo (Seade; Suzigan apud Lencioni, 2003). A partir da década de 1970, e intensificando-se nos anos 1980, inicia-se no Estado de São Paulo uma dispersão das atividades industriais do aglomerado metropolitano, com as indústrias estruturando-se em direção dos traçados das principais vias de transporte rodoviário que partem da capital paulista rumo ao interior oeste do Estado, principalmente em razão dos custos de aglomeração, como o alto preço do solo urbano, congestionamento da metrópole, aliados a problemas de 
ordem ambiental e à deterioração das condições de vida provocados pela concentração industrial.

A antiga Estrada de Itu inaugurada em 1922 e erguida sobre a trilha dos Bandeirantes às margens do Rio Tietê, hoje nominada Estrada Parque ${ }^{2}$ (Figuras 9 e 10) desde 1996 por grandes potencialidades que esta área desfruta.Inserida em uma Área de Proteção Ambiental ${ }^{3}$, nesse caso específico nas APAs Itu - Rio Tietê e Jundiaí - Cabreúva. AAPA Itu Rio Tietê é considerada área de preservação ambiental por reunir floresta da Mata Atlântica e formas de vegetação natural, cursos d'água e formações geológicas únicas compostas por morretes graníticos denominados Matacões, além de edificações de rico valor arquitetônico, histórico, cultural, artístico e turístico.

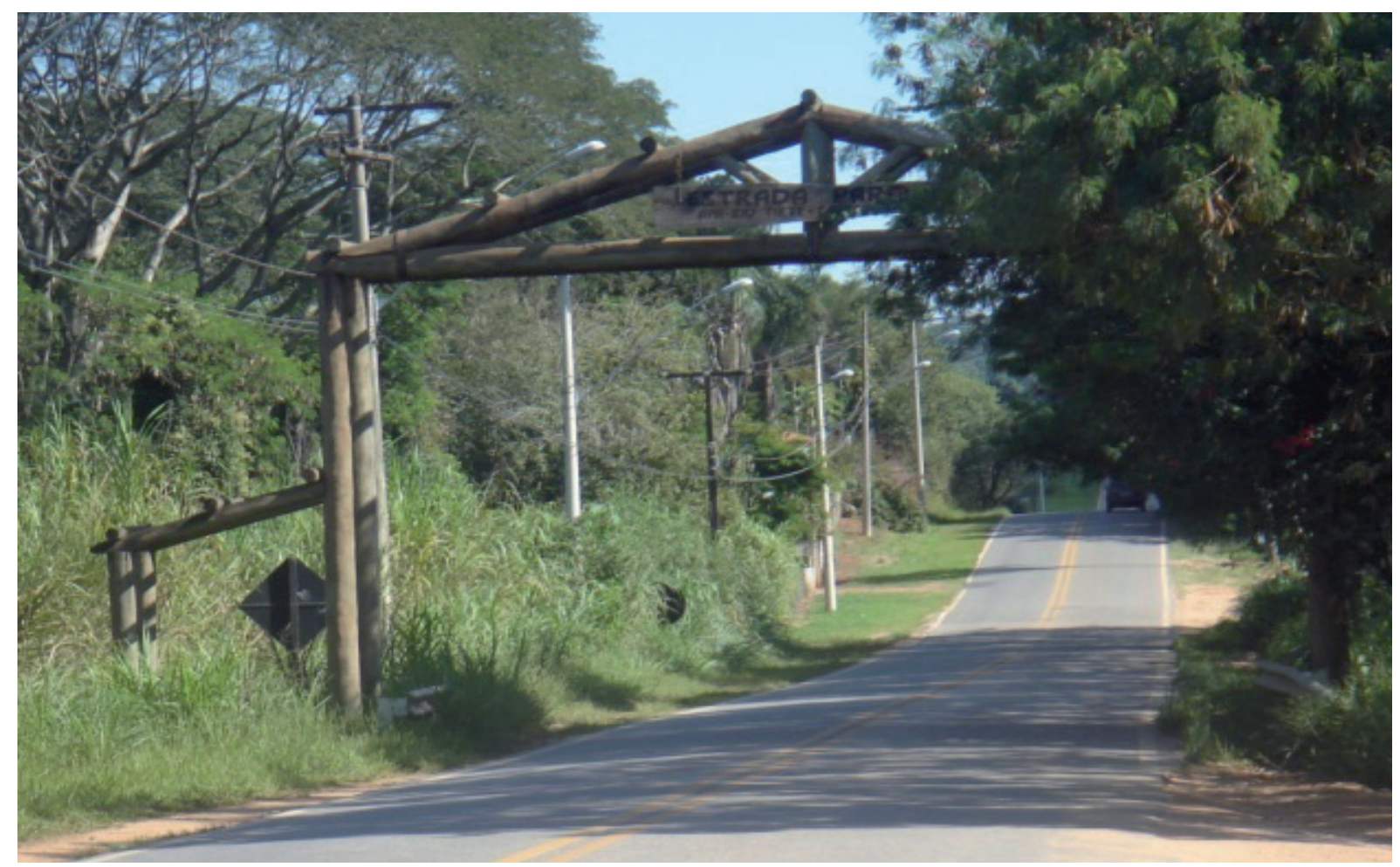

Figura 9: Portal da Estrada Parque - Itu. Fonte: Deize Sanches, 2013

\footnotetext{
2 Estrada Parque - Aprovada pela Lei Ordinária n 4020/1996 de Itu que cria a Estrada Parque "APA - Itu Rio Tietê" e dá outras providências.

${ }^{3}$ APA - Área de Proteção Ambiental é uma categoria de unidade de conservação que iniciou na década de 80, com base na Lei Federal $n^{\circ}$ 6.902, de 27 de abril de 1981, que estabelece no art. 8: "Havendo relevante interesse público, os poderes executivos Federal, Estadual ou Municipal poderão declarar determinadas áreas dos seus territórios de interesse para a proteção ambiental, a fim de assegurar o bem-estar das populações humanas, a proteção, a recuperação e a conservação dos recursos naturais".
} 




Figura 10: Estrada Parque com vista do Rio Tietê - Itu. Fonte: Deize Sanches, 2013

\section{OBJETIVO}

Esta pesquisa tem como objetivo mostrar a importância da biodiversidade e do turismo regional para a resiliência urbana das cidades de Itu, Cabreúva e Salto. Percebese um forte indicativo do potencial turístico e ambiental da região, podendo agregar valores sustentáveis aos municípios da área de estudo, com a criação de diretrizes voltadas à infraestrutura do turismo regional (romarias), à conservação da diversidade das unidades de paisagem e unidades de conservação junto ao Rio Tietê, à preservação das áreas de proteção ambiental (APA) ${ }^{4}$ - APAs Itu - Rio Tietê e Jundiaí - Cabreúva; alguns dos últimos redutos de Mata Atlântica no interior do Estado de São Paulo, e à valorização dos bens tombados.

A APA Itu Rio Tietê é uma complexa área de diversidade de ecossistemas e biodiversidade, colaborando com inúmeros serviços ecossistêmicos: aumento do armazenamento de carbono e sua absorção, redução do consumo global de energia com

\footnotetext{
${ }^{4}$ APA - Área de Proteção Ambiental, no caso específico, a APA Itu - Rio Tietê.
} 
sombreamento e refrigeração das árvores, redução do efeito ilha de calor e redução das temperaturas, conservação do ciclo hidrológico entre outros.

A Estrada Parque pode ser vista como um elemento essencial de conexão aos ecossistemas fragmentados, criando uma reserva da Biosfera ou corredor verde de ligação entre os municípios de Cabreúva, Itu e Salto; possibilitando a introdução de plantas e espécies animais, plantio de plantas nativas na própria estrada e aos arredores, plantio de pequenas hortas para habitats de polinizadores nativos, entre outros. Assim, percebemos que existem muitas ferramentas para ajudar as cidades a gerenciar sua biodiversidade e conectar seus ecossistemas fragmentados.

O conceito de Estrada Parque (estrada ecológica, estrada panorâmica, estrada cênica, estrada verde ou estrada ambiental) vem da terminologia "parkway", criada por Calvert Vaux e Frederick Law Olmsted no século XIX (FORMAN, 1986) para definir um tipo de estrada segregada para pedestres, bicicletas, cavalos e carruagens, com a intenção de contemplação da paisagem, de acordo com Giordano (2004) e Friedrich (2007). O primeiro projeto de Olmsted utilizando o conceito de parkway ocorreu no Brooklin em 1866, com o Park ${ }^{5}$. Atualmente, este parque linear faz parte do conjunto do Brooklyn-Queens Greenway (FRANCO, 2001). A partir daí, Olmsted projetou uma série de "parkways" em diversas cidades dos Estados Unidos, como Nova York, São Francisco, Búfalo, Detroit, Chicago e Boston, tendo ainda influenciado outros arquitetos paisagistas que também aplicaram este conceito, como Charles Eliot, Jeans Jensen e Robert Moses (FRANCO,1997).

De acordo com a National Scenic Byways Program ${ }^{6}$, as parkways são estradas caracterizadas pelos seus aspectos singulares em termos arqueológicos, culturais e históricos, além de possuírem áreas naturais e de recreação com um alto potencial cênico, já a Fundação SOS Mata Atlântica (2004), define: "Estrada Parque é um museu permanente de percurso que atravessa Unidades de Conservação ou áreas de relevante interesse ambiental e paisagístico, implantado com o objetivo de aliar a preservação ambiental ao desenvolvimento sustentável da região por meio do fomento do ecoturismo e das atividades de educação ambiental, de lazer e culturais. Trata-se de uma

\footnotetext{
${ }^{5}$ Brooklyn'sProspect Park - É um oásis localizado no coração de Brooklyn, bairro mais populoso de Nova York. Foi projetado por Frederick Law Olmsted e CalvertVaux, os mesmos que fizeram o Central Park.

${ }^{6}$ NATIONAL SCENIC BYWAYS PROGRAM - Programa Americano criado em 1991 com a intenção de destacar uma coleção distinta de estradas cênicas com suas histórias e lugares interessantes.
} 
classificação especial para rodovias e estradas localizadas em áreas de exuberância cênica e de relevante interesse patrimonial, quer seja natural, ambiental, arqueológico, cultural ou paisagístico, que podem ser tombadas ou especialmente protegidas."

A biodiversidade e os serviços ecossistêmicos podem ser definidos como capital natural, ou seja, estoque de bens e serviços providos pelos ecossistemas e essencial à humanidade, conceito esse descrito no estudo global "The Economics of Ecosystems and Biodiversity - TEEB" (A Economia dos Ecossistemas e da Biodiversidade). Em nossa área de estudo, o potencial e o reconhecimento do valor dos serviços prestados pelos ecossistemas são fundamentais para um planejamento urbano sustentável; se não formos capazes de incorporá-los, o resultado será "business as usual" (Negócios como de costume); degradação ambiental e o uso indevido dos recursos naturais.

Outro fator que irá integrar a biodiversidade ao turismo regional aos municípios da área de estudo, é a saúde do ser humano. Introduzir um turismo saudável à população, sem a intenção de degradação dos recursos naturais; como água e ar limpos, saneamento eficaz e gestão saudável dos animais é à base de uma saúde pública urbana. Os benefícios da saúde que derivam do contato direto com os ecossistemas vão desde a melhoria da função imunológica, humor e concentração, redução do estresse e benefícios no exercício físico. A Organização Mundial da Saúde (OMS) define a interligação entre saúde humana e meio ambiente como "um estado de completo desenvolvimento físico, mental e bem-estar social".

Existe uma relação direta entre a biodiversidade e a segurança alimentar nas cidades. A biodiversidade na alimentação urbana desempenha um papel fundamental na luta contra a fome e os problemas de saúde. O rápido crescimento das cidades é um desafio para a capacidade da agricultura de prover alimentos a nível local e global. A agricultura e a biodiversidade na alimentação são componentes-chaves de dietas sustentáveis e culturalmente aceitáveis, influenciando diretamente na educação e no modo de pensar da população. A educação ambiental baseada na relação entre alimentação, saúde e biodiversidade pode oferecer melhores condições para a implantação de um turismo regional consciente, sem agredir o meio ambiente. Educação para o Desenvolvimento Sustentável (EDS) é uma estratégia fundamental ao longo das últimas décadas para encorajar mudanças de comportamento que irão criar um futuro mais sustentável. Seus principais componentes são: visão inovadora e holística da educação, abordagem interdisciplinar que promove biodiversidade urbana e desenvolvimento urbano sustentável, valores e visão de futuro, estratégia pedagógica 
dinâmica e participativa e o processo cooperativo que envolve diversas partes interessadas.Como centros importantes para a diversidade, as cidades são um campo de testes para a nossa capacidade de viver juntos e de criar ambientes que são socialmente justos, ecologicamente sustentáveis, economicamente produtivos, politicamente participativos e culturalmente vibrantes. A educação ambiental é vital para a tarefa de adquirir esta capacidade.

\section{MÉTODOS}

Uma importante ferramenta para se avaliar como o desenvolvimento urbano está interferindo na Biodiversidade urbana é o Projeto GEO Cidades. É uma iniciativa lançada pelo Programa das Nações Unidas para o Meio Ambiente (PNUMA) em 2000, especificamente para a América Latina e o Caribe, que procura fornecer aos governos nacionais, cientistas, tomadores de decisão e ao público em geral informações atuais e de fácil entendimento sobre suas cidades, visando à melhoria ambiental e socioeconômica.

O Global Environment Outlook (GEO), um projeto iniciado em 1995 pelo (PNUMA) para avaliar o estado do meio ambiente nos níveis global, regional e nacional, além de propiciar uma avaliação do estado do meio ambiente e das regiões, utiliza um processo participativo que ajuda a fortalecer os conhecimentos e as capacidades técnicas de atuação na área ambiental através da construção de um consenso sobre os assuntos ambientais prioritários e da formação de parcerias.

Na metodologia GEO Cidades, a análise tem como foco a interação entre o desenvolvimento urbano e o meio ambiente; e tal interação baseia-se no uso da matriz (PEIR) Pressão - Estado - Impacto - Resposta, que define e relaciona o grupo de fatores determinantes das características que influenciam o meio ambiente em qualquer escala territorial (local, regional, nacional, global). A matriz PEIR procura estabelecer um vínculo lógico entre seus componentes de forma a dirigir a avaliação do estado do meio ambiente, desde os fatores que estabelecem uma pressão sobre os recursos naturais (e que podem ser entendidos como as "causas" do seu atual estado), até cada uma das respostas locais acerca de como lidar com seus próprios problemas ambientais.

Os componentes da matriz PEIR são definidos da seguinte forma e com as seguintes questões: 
Estado é a condição do meio ambiente, resultante das pressões; por exemplo, o nível de poluição atmosférica, a erosão do solo ou o desmatamento. $\mathbf{O}$ que está acontecendo com o meio ambiente?

Pressão são as forças econômicas e sociais subjacentes, como o crescimento da população, o consumo e a pobreza. De uma perspectiva política, a pressão constitui o ponto de partida para o enfrentamento dos problemas ambientais. Por que isto está acontecendo?

Impacto é o efeito produzido pelo estado do meio ambiente sobre aspectos como a qualidade de vida e a saúde humana, sobre o próprio meio ambiente, sobre o ambiente construído e sobre a economia urbana. Qual é o impacto causado pelo estadodo meio ambiente (ar, água, solo, biodiversidade e meio ambiente construído)?

Resposta são as ações coletivas ou individuais que atenuam ou previnem impactos ambientais negativos,corrigem os danos causados ao meio ambiente, preservam os recursos naturais ou contribuem para a melhoria da qualidade de vida da população local.

As respostas podem incluir as ações de regulação dos custos ambientais ou de pesquisa, a opinião pública e as preferências dos consumidores, mudanças nas estratégias administrativas e o fornecimento de informações sobre o meio ambiente. Conhecer as formas por meio das quais a sociedade responde aos problemas ambientais, demanda mais trabalho de análise e interpretação por parte da equipe local. Os instrumentos incluídos nesta dimensão da matriz procuram responder à questão: $\mathbf{O}$ que acontecerá se não atuarmos agora?

É fundamental orientar a análise dos cenários futuros do meio ambiente local a partir da avaliação do seu estado atual. A lógica subjacente à matriz PEIR permite estabelecer uma ponte para projetar futuras manifestações das atuais condições ambientais, estimulando a análise das possíveis conseqüências das ações atuais. Isso abre a possibilidade de se definir ações estratégicas capazes de mudar o rumo dos problemas ambientais de cada localidade.

\section{RESULTADOS ESPERADOS}

Uma vez que a urbanização está mudando drasticamente a natureza do nosso plane- 
ta, a preservação da biodiversidade exige ir muito além da tradicional abordagem de proteger e conservar, devemos criar metas e diretrizes de projetos urbanos com novos tipos de ecossistemas que permitam a reconciliação entre o desenvolvimento urbano e a biodiversidade. Abordar a urbanização e os desafios da biodiversidade exigirá uma melhor governança em várias escalas, particularmente no nível da cidade.

A metodologia GEO cidades pressupõe que o desenvolvimento sustentável traz novas demandas para a avaliação e o relatório, tais como: reconhecer os vínculos entre as condições ambientais e as atividades humanas, especialmente aquelas relacionadas com o desenvolvimento urbano, destacar a necessidade de se adotar uma perspectiva de longo prazo, considerar a igualdade e encorajar a participação de todos os setores da sociedade no processo de tomada de decisão.

As cidades têm um papel central a desempenhar na promoção da sustentabilidade global, como centros de inovação humana, criatividade e aprendizagem, assim como, fortalecera biodiversidade é essencial para o desafio mundial em fase de urbanização.

O planejamento urbano e ambiental deve oferecer oportunidades e mecanismos para integrar à proteção da biodiversidade e sincronizar ações verticais (níveis internacional, nacional, estadual, local) e horizontais (transporte, educação, economia, planejamento, meio ambiente), somando-se a essa, instituições públicas, grupos de cidadãos, cientistas, empresas e outras.

Assim, temos um panorama da nossa área de estudo; uma região em crescente desenvolvimento socioeconômico, que merece um estudo mais aprofundado da sua biodiversidade e do seu potencial turístico, que envolve os patrimônios natural, paisagístico, histórico, cultural e religioso regionais para promover a resiliência das cidades de Itu, Salto e Cabreúva, oferecer novas propostas de planejamento urbano sustentável, colaborar com possíveis intervenções dos órgãos públicos estaduais e municipais na formulação e revisão de planos diretores e contribuir com a valorização das potencialidades dos municípios regionais. 


\section{REFERÊNCIAS}

AB' SABER, Aziz Nacib. Os Domínios de Natureza no Brasil: Potencialidades Paisagísticas. São Paulo: Ateliê Editorial, 2003.

ALBERTI, M. et al. (2003), "Integrating Humans into Ecology: Opportunities and Challenges for Studying Urban Ecosystems”. Bio Science, 53, 1169-1179;

BRUNDTLAND, G. H. Our Common Future: The World Commission on Environment and Development. Oxford: Oxford UniversityPress,1987.

CARPI JUNIOR, S. Bases Geográficas para o Estudo do Patrimônio Natural do Vale do Médio Tietê - São Paulo - SP. In Contribuições Geográficas, org. Torres, F.T. P.; Dagnino, R. S. \& Oliveira JR, A. Ed. Geographica, Ubá, MG, 2009.

CARPI JUNIOR, S. A Geografia Regional - hidrografia e geomorfologia. In: ZEQUINI, A.; KREIDLORO, C.; FERRARI, I. Panorama Histórico - geográfico do Vale Médio Tietê: 500 anos de Brasil. Itu (SP): Ottoni Editora, 2000.

CARVALHO, R. M. Povoamento da Região de Itu: Índios, Colonizadores e Jesuítas. In: ZEQUINI, A.; KREIDLORO, C.; FERRARI, I.(Org.). Panorama Histórico - geográfico do Vale Médio Tietê: 500 anos de Brasil. Itu (SP): OttoniEditora, 2000.

CSIRO, A Research Prospectus for Urban Resilience. A Resilience Alliance Initiative for Transitioning Urban Systems towards Sustainable Futures, 2007.

COLDING, J. Ecological land-use complementation for building resilience in urbanecosystems.LandscapeandUrban Planning, 2007.

Convenção Sobre Diversidade Biológica (CBD), Conferência das Nações Unidas sobre o Meio Ambiente e o Desenvolvimento, Rio de Janeiro, 1992.

ELMQVIST, T.; FRAGKIAS, M.; GUNERALP, B.; MARCOTULLIO, P.; MCDONALD, R.; PARNELL, S.; SENDSTAD, M.; SETO, K. e WILKINSON, C.. Cities and Biodiversity Outlook (CBO) - Action and Policy.Stockholm Resilience Centre - Stockholm University, 2013. 
FIBGE, Censo Demográfico de 1991, Fundação Instituto Brasileiro de Geografia e Estatística, 1991.

FRANCO, Maria Assunção Ribeiro. Desenho ambiental - Uma Introdução à Arquitetura da Paisagem com o Paradigma Ecológico. São Paulo: Annablume/Fapesp, 1997.

FRANCO, Maria de A. R. Planejamento Ambiental para a Cidade Sustentável. São Paulo, Annablume/EDIFURB, 2ª́Ed., 2001.

FUNDAÇÃO SOS MATA ATLÂNTICA. Estrada Parque, Conceito, Experiências e Contribuições. São Paulo: Estúdio Girassol/Esperança Sobral, 2004.

HERZOG, Cecília. Inverde. Instituto de Pesquisas em Infraestrutura Verde e Ecologia Urbana. http://inverde.wordpress.com/ acesso em 12/abril/2013.

IBGE. Censo Demográfico 2010, Instituto Brasileiro de Geografia e Estatística, 2010.

INSTITUTO GEOGRÁFICO E CARTOGRÁFICO (IGC). Mapa Geomorfológico do Estado de São Paulo, Escala 1:1. 000.000. São Paulo, 1981.

LEI MUNICIPAL no. 4020/1996. “APA - ITU RIO TIETÊ - SP 312”, Itu, 1996.

MASCARÓ, Juan Luis e YOSHINAGA, Mário. Infra-estrutura urbana. Porto Alegre: L. Mascaró, J. Mascaró, 2005.

MORELLATO, L.P.C. História Natural da Serra do Japi: Ecologia e Preservação de uma Área Florestal no Sudeste do Brasil. Editora UNICAMP/FAPESP, Campinas, 1992.

PICKETT, S.; CADENASSO, M. e GROVE, J., "Resilient cities: meaning, models, andmetaphor for integrating the ecological, socio-economic, and planning realms".Landscape and Urban Planning, 2004.

PNUMA. Programa das Nações Unidas para o Meio Ambiente, Metodologia para a elaboração de Relatórios GEO Cidades, 2004.

REDMAN, C. e JONES N. (2005), "The environmental, social and health dimensions of urban expansion". Population and Environment, 26, 505-520. 
REIS, Nestor Goulart. Dois Séculos de Projetos no Estado de São Paulo: Grandes Obras e Urbanização. São Paulo: Editora da USP: Imprensa Oficial, 2010.

Roteiro dos Bandeirantes. http://www.roteirodosbandeirantes.com.br/. Acesso em 20/ maio/2013.

SACHS, Ignacy. Caminhos para o Desenvolvimento Sustentável.Garamond, Rio de Janeiro, 2002.

SANCHES, Deize Sbarai. Avaliação da Qualidade Ambiental no Projeto Urbano: Complexo Riviera de São Lourenço. Florianópolis. 2008. Dissertação de Mestrado. Universidade Federal de Santa Catarina.

Secretaria de Turismo do Estado de São Paulo. http://www.turismo.sp.gov.br/. Acesso em 13/maio/2013.

SCIFONI, S. A Construção do Patrimônio Natural. Tese Doutorado - Universidade de São Paulo, Instituto de Geografia, São Paulo, 2006.

SILVA, M. C. V.; Viadana, A.G. A Paisagem de Enclave de Itu-Salto (SP - Brasil) Sob a Ótica da Teoria dos Refúgios Florestais. In: Anais do X Encontro de Geógrafos da América Latina. Universidade de São Paulo, 2005.

WALKER, B.; Holling, C.; Carpenter, S. e Kinzig, A. Resilience, Adaptability and Transformability in Social-Ecological Systems. EcologyandSociety, 2004.

www.ined.fr/. Acesso em 29/novembro/2013.

www.worldometers.info. Acesso em 29/novembro/2013. 